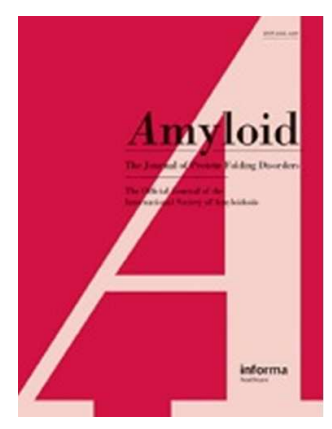

\title{
Carpal tunnel syndrome: a common initial symptom of systemic wild-type ATTR (ATTRwt) amyloidosis
}

\begin{tabular}{|r|l|}
\hline Journal: & Amyloid \\
\hline Manuscript ID & DAMY-2015-0082.R2 \\
\hline Manuscript Type: & Original Article \\
\hline Date Submitted by the Author: & 20-Dec-2015 \\
\hline Complete List of Authors: & $\begin{array}{l}\text { Nakagawa, Michitaka; Shinshu University School of Medicine, Department } \\
\text { of Medicine (Neurology and Rheumatology) } \\
\text { Sekijima, Yoshiki; Shinshu University School of Medicine, Department of } \\
\text { Medicine (Neurology and Rheumatology) } \\
\text { Yazaki, Masahide; Shinshu University School of Medicine, Department of } \\
\text { Medicine (Neurology and Rheumatology) } \\
\text { Tojo, Kana; Shinshu University School of Medicine, Department of Medicine } \\
\text { (Neurology and Rheumatology) } \\
\text { Yoshinaga, Tsuneaki; Shinshu University School of Medicine, Department of } \\
\text { Medicine (Neurology and Rheumatology) } \\
\text { Doden, Tadashi; Shinshu University School of Medicine, Department of } \\
\text { Medicine (Neurology and Rheumatology) } \\
\text { Koyama, Jun; Shinshu University School of Medicine, } \\
\text { Yanagisawa, Shin; Shinshu University School of Medicine, Radiology } \\
\text { Ikeda, Shu-ichi; Shinshu University School of Medicine, Department of } \\
\text { Medicine (Neurology and Rheumatology) }\end{array}$ \\
\hline Keywords: & $\begin{array}{l}\text { wild-type ATR amyloidosis, senile systemic amyloidosis, carpal tunnel } \\
\text { syndrome, transthyretin, amyloid }\end{array}$ \\
\hline \hline
\end{tabular}

\section{SCHOLARONE}

Manuscripts 


\section{Carpal tunnel syndrome: a common initial symptom of systemic wild-type ATTR}

\section{(ATTRwt) amyloidosis}

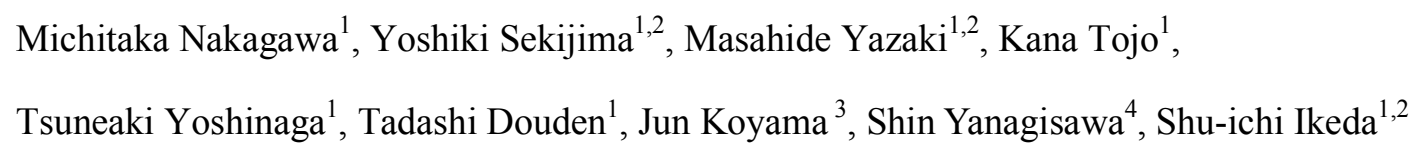

${ }^{1}$ Department of Medicine (Neurology and Rheumatology), Shinshu University School of Medicine, 3-1-1 Asahi, Matsumoto 390-8621, Japan.

${ }^{2}$ Institute for Biomedical Sciences, Shinshu University, 3-1-1 Asahi, Matsumoto 390-8621, Japan.

${ }^{3}$ Department of Cardiovascular Medicine, Shinshu University School of Medicine, 3-1-1 Asahi, Matsumoto 390-8621, Japan.

${ }^{4}$ Department of Radiology, Shinshu University School of Medicine, 3-1-1 Asahi, Matsumoto 390-8621, Japan.

Correspondence: Yoshiki Sekijima, Department of Medicine (Neurology and Rheumatology), Shinshu University School of Medicine, 3-1-1 Asahi, Matsumoto 390-8621, Japan.

TEL +81-263-37-2673, FAX +81-263-37-3427, E-mail sekijima@shinshu-u.ac.jp

Running head: Carpal tunnel syndrome in ATTRwt amyloidosis 


\begin{abstract}
Background: Systemic wild-type ATTR (ATTRwt) amyloidosis is a prevalent aging-related disorder. However, a limited number of systemic ATTRwt amyloidosis patients have been diagnosed antemortem, and therefore the prevalence of ATTRwt is underestimated. Here, we investigated clinical findings of a series of systemic ATTRwt amyloidosis patients with ante-mortem diagnosis.
\end{abstract}

Methods: Thirty-one consecutive patients diagnosed with systemic ATTRwt amyloidosis at Shinshu University Hospital were included in this study. Systemic ATTRwt amyloidosis was diagnosed based on proven ATTR amyloid deposition in biopsy specimens and confirmation of wild-type TTR genotype.

Results: The systemic ATTRwt amyloidosis patients consisted of 24 men and 7 women, and mean age of onset was $69.8 \pm 9.0$ years. The most common initial symptom was carpal tunnel syndrome (CTS, 17 patients), followed by heart failure symptoms (14 patients). The mean age at diagnosis was $74.5 \pm 8.3$ years and the duration of illness from onset to diagnosis was $5.4 \pm$ 4.4 years. Cardiogenic embolism and renal dysfunction are also frequently seen during the course of the disease.

Conclusions: CTS is the most common initial symptom of systemic ATTRwt amyloidosis.

Our results suggest the possibility of systemic ATTRwt amyloidosis diagnosis at an early stage by carefully examining patients with CTS. 
Keywords Wild-type ATTR (ATTRwt) amyloidosis, senile systemic amyloidosis, carpal tunnel syndrome, transthyretin, amyloid

\begin{abstract}
Abbreviations:
ATTRwt amyloidosis: wild-type ATTR amyloidosis; BNP: brain natriuretic peptide; CTS: carpal tunnel syndrome; DT: E-wave deceleration time; E/A ratio: ratio of the early to late ventricular filling velocities; ECG: electrocardiogram; E/e' ratio: Ratio of early mitral inflow velocity to mitral annular early diastolic velocity; FS: fractional shortening; IVSThd: diastolic thickness of the interventricular septum; LVDd: left ventricular diastolic diameter; LVEF: left ventricular ejection fraction; PCR: polymerase chain reaction; siRNAs: small interfering RNAs; ${ }^{99 \mathrm{~m}}$ Tc-PYP : Technetium-99m pyrophosphate; TTR: transthyretin
\end{abstract}




\section{Introduction}

Systemic wild-type ATTR (ATTRwt) amyloidosis (also called senile systemic amyloidosis) is an incurable sporadic disease caused by extracellular deposition of amyloid fibrils composed of wild-type transthyretin (TTR) [1]. Systemic ATTRwt amyloidosis is a prevalent aging-related disorder, as $12 \%-25 \%$ of people over the age of 80 and $37 \%$ of people over the age of 95 were shown to have ATTR deposition in postmortem studies [2-4]. However, a limited number of systemic ATTRwt amyloidosis patients have been diagnosed antemortem, probably due to reduced attention given to ATTRwt amyloidosis as no effective disease-modifying therapies are currently available for this disease. An alternative rationale or explanation for the low rate of antemortem diagnosis is that ATTR amyloid deposits found on autopsy do not contribute to the clinical syndromes that patients experience in a certain proportion of cases.

Recently, however, the clinical effects of TTR tetramer stabilizers, diflunisal [5] and tafamidis [6], on hereditary ATTR amyloidosis were demonstrated in randomized clinical trials, and tafamidis has been approved for treatment of hereditary ATTR amyloidosis in several European countries, Japan, Argentina, and Mexico. In addition, gene therapies with antisense oligonucleotides [7] and small interfering RNAs (siRNAs) [8] are promising strategies for amelioration of ATTR amyloidosis and are currently in Phase III clinical trials. Based on their mechanisms of action, these newly developed therapies are expected to be effective for not only hereditary ATTR amyloidosis but also ATTRwt amyloidosis. Importanlty, both TTR 
tetramer stabilizers and gene silencers are expected to prevent amyloid deposition but do not address amyloid already present. Therefore, early diagnosis and therapy will be required in systemic ATTRwt amyloidosis.

Here, we present the clinical, radiological, and pathological findings of a series of systemic ATTRwt amyloidosis patients with antemortem diagnosis and discuss indicators for the early diagnosis of this disease. We reported, for the first time, the high prevalence of CTS in systemic ATTRwt and showed that CTS is the most common initial symptom of the disease. Our findings suggest the possibility of systemic ATTRwt amyloidosis diagnosis at an early stage by careful examination of patients with CTS.

\section{Materials and Methods}

\section{Patients}

Thirty-one consecutive patients diagnosed with systemic ATTRwt amyloidosis and evaluated at Shinshu University between February 2008 and August 2015 were included in this study. Systemic ATTRwt amyloidosis was diagnosed based on proven ATTR amyloid deposition in biopsy specimens and confirmation of wild-type TTR genotype (i.e., all patients were diagnosed as systemic ATTRwt by Congo red/immunohistochemical analysis and DNA analysis). Patients with localized tenosynovium ATTRwt amyloidosis were excluded from the study. 


\section{Methods}

\section{Analysis of clinical findings}

We performed diagnostic interviews with patients and their family members very carefully at the first medical examination and followed up at least once a year. Additional telephone interviews with patients and their families, and inquiries to other hospitals that the patients had consulted were performed in cases in which medical information was insufficient. All patients were evaluated by neurologists, and no ATTRwt patients had obvious cognitive dysfunction. Initial symptoms were defined as symptoms considered to be related to ATTRwt amyloidosis. We regarded cardiac symptoms, cardiogenic embolism, CTS, and peripheral neuropathy as ATTRwt-related symptoms based on previous reports. All symptoms related to other diseases were excluded from ATTRwt-related symptoms. Age at onset was defined as the age when ATTRwt-related symptoms first developed. Patient history, laboratory, radiological, and pathological findings were retrospectively obtained from medical records.

\section{Congo red and immunohistochemical analysis}

Biopsy tissues specimens were analyzed by phenol Congo red and immunohistochemical staining. Immunohistochemical analysis was performed as follows. After deparaffinization, sections were treated with Peroxidase-Blocking Solution (Dako, Glostrup, Denmark) to inhibit endogenous peroxidase activity and with Protein Block, Serum-Free (Dako, Carpinteria, CA) to inhibit nonspecific binding. Anti- $\lambda$ (118-134), anti- $\kappa$ (116-133) [9], anti-AA [10], and anti-TTR (115-124) [11] antibodies were applied to the sections as primary antibodies for 30 
minutes at room temperature. The sections were then incubated with EnVision+ (Dako) as the secondary antibody for 30 minutes at room temperature. Immunoreactivity was visualized with DAB+ (3, 3-Diaminobenzidine, Dako).

\section{DNA analysis for detecting TTR mutations}

Direct DNA sequencing of the entire TTR gene were performed to detect TTR gene mutations. DNA was extracted from peripheral leukocytes of the patients according to the standard protocol after obtaining written informed consent. All four exons of the TTR gene were amplified by polymerase chain reaction (PCR) and the PCR-amplified DNAs were analyzed by direct sequencing.

\section{Technetium-99m pyrophosphate $\left({ }^{99 \mathrm{~m}} \mathrm{Tc}-\mathrm{PYP}\right)$ myocardial scintigraphy}

Myocardial scintigraphy with ${ }^{99 \mathrm{~m}} \mathrm{Tc}-\mathrm{PYP}$ was performed using a triple-head gamma camera (PRISM IRIX; Shimadzu, Kyoto, Japan) equipped with low-energy, high-resolution (LEHR) collimators. Patients received $15-20 \mathrm{mCi}$ of ${ }^{99 \mathrm{~m}} \mathrm{Tc}-\mathrm{PYP}$ intravenously, and planar images (anterior, lateral and left anterior oblique views) with the heart centered in the field of view were obtained approximately 3.5 hours after injection. The parameters of acquisition were as follows: matrix $=512 \times 512$, zoom factor $=1.422$, acquisition time $=240$ s. In addition, SPECT images were obtained with the following acquisition parameters: matrix $=64 \times 64$, zoom factor $=1.488$. The Butterworth filter was used with a cutoff of 0.24 cycle/pixel and order of 8.00. Results of ${ }^{99 \mathrm{~m}} \mathrm{Tc}-\mathrm{PYP}$ myocardial scintigraphy (i.e., positive or negative) were assessed by radiologists. 


\section{Statistical analysis}

Statistical comparisons were performed between the cardiac symptom onset group and carpal tunnel onset group. Demographic data of both groups were assessed using the $\chi^{2}$ test for binary outcomes. For continuous variables, we used the Mann-Whitney U test (when data were not normally distributed), Student's $t$ test (when data had a normal distribution with equal variance), or Welch's $t$ test (when data had a normal distribution with unequal variance). All statistical analyses were conducted using SPSS version 18.0J software (SPSS Inc., Chicago, IL). In all analyses, $P<0.05$ was taken to indicate statistical significance.

\section{Results}

\section{Demographic characteristics and initial symptoms of ATTRwt amyloidosis patients}

The clinical features of systemic ATTRwt amyloidosis patients are summarized in Supplemental Table 1. The systemic ATTRwt amyloidosis patients consisted of 24 men and 7 women (male-female ratio, 3.4:1), and the age of onset ranged from 44 to 97 years (mean \pm $\mathrm{SD}, 69.8 \pm 9.0)$. The female ratio in our series was higher than those in previous reports (male-female ratio, 25 - 50:1) [12-14]. In addition, the average age of onset in women (79.0 \pm 8.5 years old) was significantly older than that in men $(67.1 \pm 7.2$ years old, $P=0.001)$ in our series.

The most common initial symptom was CTS ( $\mathrm{n}=17,55 \%)$, followed by heart failure symptoms $(n=14,45 \%)$. The age at diagnosis ranged from 47 to 97 years (mean $\pm S D, 74.5 \pm$ 
8.3) and the duration of illness from onset to diagnosis was $0-16$ years (mean $\pm \mathrm{SD}, 5.4 \pm$

4.4). The duration of illness from first cardiac symptoms to diagnosis was $2.1 \pm 2.8$ years.

Confirmation of ATTR amyloid deposition by tissue biopsy and myocardial scintigraphy

ATTR amyloid deposition was confirmed by endomyocardial biopsy in 17 patients (55\%), gastroduodenal mucosa biopsy in 16 patients (52\%), surgical skin biopsy including the deep subcutaneous fat pad in 10 patients (32\%), and tenosynovial tissues obtained at carpal tunnel release surgery in 6 patients $(19 \%) .{ }^{99 \mathrm{~m}} \mathrm{Tc}-\mathrm{PYP}$ myocardial scintigraphy was performed in 24 patients and abnormal uptake was observed in 23 patients. The patient that did not have abnormal uptake was a 47-year-old male (patient 20 in Supplemental Table 1) diagnosed based on tenosynovial tissues obtained at carpal tunnel release surgery and gastroduodenal mucosa biopsy. Detailed clinical findings of this patient were described previously [15]. Two patients had abnormal uptake in ${ }^{99 \mathrm{~m}} \mathrm{Tc}-\mathrm{PYP}$ myocardial scintigraphy, although they did not have cardiac symptoms or signs.

\section{Cardiac manifestations}

At the time of diagnosis, 28 patients (90\%) showed cardiac manifestations, including cardiac failure/dilatation $(\mathrm{n}=25,81 \%)$, bundle branch block/intraventricular conduction delay $(\mathrm{n}=15,48 \%)$, atrial fibrillation $(\mathrm{n}=13,42 \%)$, atrioventricular block $(\mathrm{n}=9,29 \%)$, sick sinus syndrome $(n=4,13 \%)$, and ventricular tachycardia/fibrillation $(n=3,10 \%)$. Three patients received a permanent pacemaker for complete atrioventricular block and one patient received an implantable cardioverter defibrillator. Plasma level of brain natriuretic peptide (BNP) was 
$284.6 \pm 186.4 \mathrm{pg} / \mathrm{mL}$ (normal, $\leq 20.0$ ).

Twenty-seven patients underwent echocardiography. The diastolic thickness of the interventricular septum (IVSThd) ranged from 9.8 to $24.1 \mathrm{~mm}$ (mean $\pm \mathrm{SD}, 19.0 \pm 4.5$; normal, $\leq 12.0)$, and hypertrophy was observed in 24 patients $(89 \%)$. The left ventricular diastolic diameter (LVDd) ranged from 14.4 to $53.9 \mathrm{~mm}$ (mean $\pm \mathrm{SD}, 42.2 \pm 7.8$; normal, $\leq 54.0$ ). Left ventricular ejection fraction (LVEF) and fractional shortening (FS) were 43.8\% $\pm 17.2 \%$ (normal, $\geq 55$ ) and $24.2 \% \pm 8.5 \%$ (normal, $\geq 28$ ), respectively, and decreased systolic function was observed in 18 patients (67\%). Ratio of the early to late ventricular filling velocities (E/A ratio) and E-wave deceleration time (DT) were $1.80 \pm 1.04$ and $178.6 \pm 49.4$, respectively. Ratio of early mitral inflow velocity to mitral annular early diastolic velocity (E/e' ratio) was evaluated in 26 patients and diastolic dysfunction (E/e' $\geq 15)$ was observed in 23 patients $(89 \%$; mean $\pm \mathrm{SD}, 34.7 \pm 24.3)$.

\section{Non-cardiac manifestations}

CTS was present in 21 patients $(68 \%)$, seven of whom had a history of carpal tunnel release surgery. Eight patients developed cardiogenic embolism (cerebral infarction, $\mathrm{n}=5$, transient ischemic attack, $\mathrm{n}=1$, renal infarction, $\mathrm{n}=1$, and acute subclavian artery occlusion, $n=1)$ during the course of the illness. Four of eight patients (50\%) with cardiogenic embolism had atrial fibrillation. Mild to moderate renal dysfunction (decreased glomerular filtration rate) was observed in 14 patients (45\%), although no patients developed end-stage kidney disease or nephrotic syndrome. Spinal canal stenosis was observed in four patients (13\%) and peripheral 
polyneuropathy was observer in two patients $(6 \%)$. Symptoms and signs of autonomic dysfunction, macroglossia, or purpura were absent in all patients. Clinical, radiological, and pathological findings of a representative patient (patient 13 in Supplemental Table 1) is shown in Figure 1.

\section{Comparison between the carpal tunnel onset group and cardiac onset group}

There were no statistically significant differences in sex ratio and age at diagnosis between the carpal tunnel onset group and cardiac onset group. However, the average age of onset in the carpal tunnel onset group ( $66.5 \pm 8.6$ years) was much younger than that in the cardiac onset group ( $73.9 \pm 7.9$ years, $P=0.01$, Table 1$)$. In addition, the duration of illness from onset to diagnosis was longer $(6.9 \pm 4.2$ years $)$ in the carpal tunnel onset group than the cardiac onset group $(1.9 \pm 2.7$ years, $P<0.0001$, Table 1$)$. In the carpal tunnel onset group, CTS preceded cardiac symptoms by $1-14$ years $(6.1 \pm 4.6$ years $)$.

\section{Discussion}

Although systemic ATTRwt amyloidosis is usually associated with cardiac disease, TTR deposition is not limited to the heart and is found in systemic organs, including the aorta, lung, gastrointestinal tract, liver, kidney and connective tissues [2, 16-21]. Especially, recent studies showed that ATTRwt amyloid deposition in joints and ligaments is very common [18-22], and CTS could be an initial symptom of systemic ATTRwt amyloidosis in some patients [15, 23-25]. However, only one small epidemiological study [13] regarding this issue has been 
published to date. Rapezzi et al. [13] reported that two of 15 (13\%) systemic ATTRwt patients developed CTS. However, the prevalence of CTS may be underestimated as not all patients were evaluated by neurologists. Here, we showed, for the first time, that CTS is the most common initial symptom in systemic ATTRwt amyloidosis by careful neurological examinations. Importantly, CTS preceded cardiac symptoms by $6.1 \pm 4.6$ years in the carpal tunnel onset group. We have also previously demonstrated that wild-type ATTR deposition is commonly seen in elderly patients with idiopathic CTS [18], suggesting that these patients with localized tenosynovium ATTRwt amyloidosis have the potential to develop systemic ATTRwt amyloidosis in the future. In addition to CTS, several studies [19, 21, 22] demonstrated that ATTR amyloid deposits were frequently found in the ligamentum flavum of the lumbar spine. Interestingly, spinal canal stenosis was observed in four systemic ATTRwt amyloidosis patients in our series (lumbar spinal canal stenosis, $n=2$; cervical spinal canal stenosis, $\mathrm{n}=2$ ), although pathological examination of the ligamentum flavum was not performed.

It is clear that systemic ATTRwt amyloidosis is a prevalent aging-related disorder [2-4]; however, this disorder is rarely recognized before death, and even when diagnosed antemortem, most patients are already in the advanced stage of the disease. At present, there are no effective disease-modifying therapies for ATTRwt amyloidosis, and mean survival period from the onset of congestive heart failure symptoms is 75 months [12]. However, newly developed therapeutic strategies for hereditary ATTR amyloidosis (i.e., TTR tetramer 
stabilizers and gene therapies) are expected to be effective for ATTRwt amyloidosis. Therefore, early diagnosis of systemic ATTRwt amyloidosis will become critical in the near future. Our results suggest that early stage systemic ATTRwt amyloidosis may be diagnosed by careful examination of patients with CTS. It is important to perform pathological investigation (i.e., Congo red staining) of the tenosynovial tissues at carpal tunnel release surgery, especially in patients older than 50 years old [18]. Immunohistochemical analysis should be performed if tenosynovial tissues are positive for amyloid. In previous reports [18, 19, 26, 27], the frequencies of ATTR amyloid deposition in specimens obtained at the time of carpal tunnel release were variable $(6.7 \%-34 \%)$. These discrepancies are likely due to differences in study populations and sensitivity of anti-TTR antibodies. Recently, we analyzed 100 idiopathic CTS patients (average age 67.3 years) and showed that wild-type ATTR deposition on tenosynovial tissues was commonly observed in elderly men (prevalence rates of wild-type ATTR amyloid deposition in males and females were $65.4 \%$ and $23.0 \%$, respectively) [18]. When staining for TTR is positive, TTR gene analysis and ${ }^{99 \mathrm{~m}} \mathrm{Tc}-\mathrm{PYP}$ myocardial scintigraphy should be performed in addition to routine chest X-ray, electrocardiogram (ECG), and echocardiography, as we detected asymptomatic amyloid deposition in the heart by this type of scintigraphy.

Considering the high sensitivity of ${ }^{99 \mathrm{~m}} \mathrm{Tc}-\mathrm{PYP}$ myocardial scintigraphy, this test could also be used as a screening test for ATTRwt in patients with ventricular hypertrophy and arrhythmia of unknown etiology.

Another important finding in the present antemortem diagnosed case series is that 
cardiogenic embolism occurs frequently during the course of systemic ATTRwt amyloidosis.

In general, cardiogenic embolism is closely associated with atrial fibrillation, and the prevalence of atrial fibrillation (42\%) was very high in our ATTRwt series, as indicated in a recent paper by Longhi et al. [28]. Intriguingly, half of the patients with cardiogenic embolism did not show atrial fibrillation on routine 12-lead ECG and Holter ECG, although patients may have low-frequency paroxysmal atrial fibrillation. Our results indicated that ATTRwt cardiac amyloidosis itself may be a risk factor for cardiogenic embolism and atrial thrombi may be present even during sinus rhythm, as shown in $\mathrm{AL}$ amyloidosis [29, 30]. Atrial contraction velocities from echo Doppler may be useful to stratify patients regarding the risk of thromboembolism.

In addition, we showed that mild to moderate renal dysfunction is common in patients with systemic ATTRwt amyloidosis. It has been reported that the kidneys in ATTRwt amyloidosis are typically free of amyloid and renal dysfunction is rare [4, 31]; however, Westermark et al. reported that seven of 33 patients were uremic in their postmortem series [16]. Renal dysfunction in our patients was milder compared with the previous report [16], probably because we diagnosed patients antemortem. Renal dysfunction in ATTRwt amyloidosis is likely attributable to amyloid deposition in the renal medullary papillae [16]. Other possibilities accounting for renal dysfunction in ATTRwt patients include age related changes and renal dysfunction attributable to poor cardiac output. Additional investigations are required to elucidate the precise pathophysiological mechanism of renal dysfunction in 
ATTRwt amyloidosis.

Finally, confirmation of the presence of ATTR amyloid deposition by tissue biopsy is necessary for accurate diagnosis of systemic ATTRwt amyloidosis. In most diagnosed cases, tissue samples were obtained by endomyocardial biopsy; however, this is rarely performed due to its high degree of invasiveness, lack of technical expertise, and limited availability. Instead, we showed that abnormal uptake of ${ }^{99 \mathrm{~m}} \mathrm{Tc}$ in myocardial scintigraphy is highly suggestive of ATTR cardiac amyloidosis, although histopathological confirmation is necessary. We showed that gastroduodenal mucosa biopsy and surgical skin biopsy including the deep subcutaneous fat pad [32, 33], and tenosynovial tissues obtained at carpal tunnel release surgery are useful alternative histopathological tool for diagnosis of ATTRwt amyloidosis.

\section{Limitations}

Our study is limited by its retrospective design, the small sample size, and single center nature of the sample potentially limiting generalizability.

\section{Conclusions}

We reported a series of patients with antemortem diagnosis of ATTRwt amyloidosis, showing that CTS is the most common initial symptom of the disease. Our detailed clinical findings provide novel insights to increase our understanding of systemic ATTRwt amyloidosis. It is likely that systemic ATTRwt amyloidosis is markedly underdiagnosed at 
present. With the development of new drugs for treatment, major efforts should be made to increase physician awareness of ATTRwt amyloidosis and CTS.

\section{Acknowledgments}

The authors thank Ms. E. Nomura for her technical support.

\section{Declaration of interest}

This study was supported by a Grant-in-aid for Scientific Research (15K09336 to YS), a grant from Amyloidosis Research Committee, the Ministry of Health, Labour and Welfare, Japan, and a Group Research Grant for the Pathogenesis and Therapy for Intractable Neuropathy in Japan. 


\section{References}

1. Westermark P, Sletten K, Johansson B, Cornwell GG, III. Fibril in senile systemic amyloidosis is derived from normal transthyretin. Proc Natl Acad Sci U S A 1990;87:2843-5.

2. Cornwell GG, III., Murdoch WL, Kyle RA, Westermark P, Pitkanen P. Frequency and distribution of senile cardiovascular amyloid. A clinicopathologic correlation. Am J Med $1983 ; 75: 618-23$.

3. Tanskanen M, Kiuru-Enari S, Tienari P, Polvikoski T, Verkkoniemi A, Rastas S, Sulkava $\mathrm{R}$, et al. Senile systemic amyloidosis, cerebral amyloid angiopathy, and dementia in a very old finnish population. Amyloid 2006;13:164-9.

4. Ueda M, Horibata Y, Shono M, Misumi Y, Oshima T, Su Y, Tasaki M, et al. Clinicopathological features of senile systemic amyloidosis: An ante- and post-mortem study. Mod Pathol 2011;24:1533-44.

5. Berk JL, Suhr OB, Obici L, Sekijima Y, Zeldenrust SR, Yamashita T, Heneghan MA, et al. Repurposing diflunisal for familial amyloid polyneuropathy: A randomized clinical trial. JAMA 2013;310:2658-67.

6. Coelho T, Maia LF, Martins da Silva A, Waddington Cruz M, Plante-Bordeneuve V, Lozeron P, Suhr OB, et al. Tafamidis for transthyretin familial amyloid polyneuropathy: A randomized, controlled trial. Neurology 2012;79:785-92.

7. Ackermann EJ, Guo S, Booten S, Alvarado L, Benson M, Hughes S, Monia BP. Clinical 17 URL: http://mc.manuscriptcentral.com/damy 
development of an antisense therapy for the treatment of transthyretin-associated polyneuropathy. Amyloid 2012;19 Suppl 1:43-4.

8. Coelho T, Adams D, Silva A, Lozeron P, Hawkins PN, Mant T, Perez J, et al. Safety and efficacy of rnai therapy for transthyretin amyloidosis. N Engl J Med 2013;369:819-29.

9. Hoshii Y, Setoguchi M, Iwata T, Ueda J, Cui D, Kawano H, Gondo T, et al. Useful polyclonal antibodies against synthetic peptides corresponding to immunoglobulin light chain constant region for immunohistochemical detection of immunoglobulin light chain amyloidosis. Pathol Int 2001;51:264-70.

10. Imada N. Pathological study on amyloidosis. Isolation and purification of amyloid fibril protein and biochemical and immunological analysis. Yamaguchi Med J 1981;30:149-62.

11. Gustavsson A, Engstrom U, Westermark P. Mechanisms of transthyretin amyloidogenesis. Antigenic mapping of transthyretin purified from plasma and amyloid fibrils and within in situ tissue localizations. Am J Pathol 1994;144:1301-11.

12. Ng B, Connors LH, Davidoff R, Skinner M, Falk RH. Senile systemic amyloidosis presenting with heart failure: A comparison with light chain-associated amyloidosis. Arch Intern Med 2005;165:1425-9.

13. Rapezzi C, Merlini G, Quarta CC, Riva L, Longhi S, Leone O, Salvi F, et al. Systemic cardiac amyloidoses: Disease profiles and clinical courses of the 3 main types. Circulation 2009;120:1203-12. 
14. Ruberg FL, Berk JL. Transthyretin (TTR) cardiac amyloidosis. Circulation 2012;126:1286-300.

15. Kodaira M, Sekijima Y, Tojo K, Tsuchiya A, Yazaki M, Ikeda S, Hoshii Y, et al. Non-senile wild-type transthyretin systemic amyloidosis presenting as bilateral carpal tunnel syndrome. J Peripher Nerv Syst 2008;13:148-50.

16. Westermark P, Bergstrom J, Solomon A, Murphy C, Sletten K. Transthyretin-derived senile systemic amyloidosis: Clinicopathologic and structural considerations. Amyloid 2003;10 Suppl 1:48-54.

17. Pitkanen P, Westermark P, Cornwell GG, III. Senile systemic amyloidosis. Am J Pathol $1984 ; 117: 391-9$

18. Sekijima Y, Uchiyama S, Tojo K, Sano K, Shimizu Y, Imaeda T, Hoshii Y, et al. High prevalence of wild-type transthyretin deposition in patients with idiopathic carpal tunnel syndrome: A common cause of carpal tunnel syndrome in the elderly. Hum Pathol 2011;42:1785-91.

19. Sueyoshi T, Ueda M, Jono H, Irie H, Sei A, Ide J, Ando Y, et al. Wild-type transthyretin-derived amyloidosis in various ligaments and tendons. Hum Pathol 2011;42:1259-64.

20. Takanashi T, Matsuda M, Yazaki M, Yamazaki H, Nawata M, Katagiri Y, Ikeda S. Synovial deposition of wild-type transthyretin-derived amyloid in knee joint osteoarthritis patients. Amyloid 2013;20:151-5. 
21. Yanagisawa A, Ueda M, Sueyoshi T, Okada T, Fujimoto T, Ogi Y, Kitagawa K, et al. Amyloid deposits derived from transthyretin in the ligamentum flavum as related to lumbar spinal canal stenosis. Mod Pathol 2015;28:201-7.

22. Westermark P, Westermark GT, Suhr OB, Berg S. Transthyretin-derived amyloidosis: Probably a common cause of lumbar spinal stenosis. Ups J Med Sci 2014;119:223-8.

23. Kyle RA, Gertz MA, Linke RP. Amyloid localized to tenosynovium at carpal tunnel release. Immunohistochemical identification of amyloid type. Am J Clin Pathol 1992;97:250-3.

24. Takei Y, Hattori T, Gono T, Tokuda T, Saitoh S, Hoshii Y, Ikeda S. Senile systemic amyloidosis presenting as bilateral carpal tunnel syndrome. Amyloid 2002;9:252-5.

25. Takei Y, Hattori T, Tokuda T, Matsuda M, Saitoh S, Hoshii Y, Ikeda S. Senile systemic amyloidosis starting as bilateral carpal and left ulnar tunnel syndrome. Intern Med $2003 ; 42: 1050-1$.

26. Stein K, Storkel S, Linke RP, Goebel HH. Chemical heterogeneity of amyloid in the carpal tunnel syndrome. Virchows Arch A Pathol Anat Histopathol 1987;412:37-45.

27. Nakamichi KI, Tachibana S. Amyloid deposition in the synovium and ligament in idiopathic carpal tunnel syndrome. Muscle Nerve 1996;19:1349-51.

28. Longhi S, Quarta CC, Milandri A, Lorenzini M, Gagliardi C, Manuzzi L, Bacchi-Reggiani ML, et al. Atrial fibrillation in amyloidotic cardiomyopathy: Prevalence, incidence, risk factors and prognostic role. Amyloid 2015;22:147-55. 
29. Dubrey S, Pollak A, Skinner M, Falk RH. Atrial thrombi occurring during sinus rhythm in cardiac amyloidosis: Evidence for atrial electromechanical dissociation. Br Heart J $1995 ; 74: 541-4$.

30. Santarone M, Corrado G, Tagliagambe LM, Manzillo GF, Tadeo G, Spata M, Longhi M. Atrial thrombosis in cardiac amyloidosis: Diagnostic contribution of transesophageal echocardiography. J Am Soc Echocardiogr 1999;12:533-6.

31. Kyle RA, Spittell PC, Gertz MA, Li CY, Edwards WD, Olson LJ, Thibodeau SN. The premortem recognition of systemic senile amyloidosis with cardiac involvement. Am J Med 1996;101:395-400.

32. Ikeda S, Sekijima Y, Tojo K, Koyama J. Diagnostic value of abdominal wall fat pad biopsy in senile systemic amyloidosis. Amyloid 2011;18:211-5.

33. Takashio S, Izumiya Y, Jinnin M, Yamamuro M, Kojima S, Ihn H, Ogawa H. Diagnostic and prognostic value of subcutaneous tissue biopsy in patients with cardiac amyloidosis. Am J Cardiol 2012;110:1507-11. 


\section{Figure Legends}

Fig. 1 Clinical, radiological, and pathological findings of a representative ATTRwt amyloidosis patient starting with carpal tunnel syndrome followed by cerebral embolism,

\section{finally showing cardiac amyloidosis}

(A) Atrophy of hand muscles, especially in the right thenar muscle. (B) Chest X-ray showing enlarged cardiac shadow and implantation of a pacemaker. (C) Positive technetium-99m pyrophosphate myocardial scintigraphy. (D) Echocardiography showing marked symmetrical thickening of ventricular wall and interventricular septum (thickness of left ventricular posterior wall: $18.7 \mathrm{~mm}$; thickness of interventricular septum: $21.4 \mathrm{~mm})$. (E, F) Brain CT showing an area of low density in the left parietooccipital lobe. (G, H) Myocardial biopsy specimen demonstrating deposits of congophilic materials $(G)$ and apple green birefringence of the deposited materials under polarized view $(\mathrm{H})$. Amyloid deposits were positively immunolabeled with an anti-TTR antibody (I). 
G
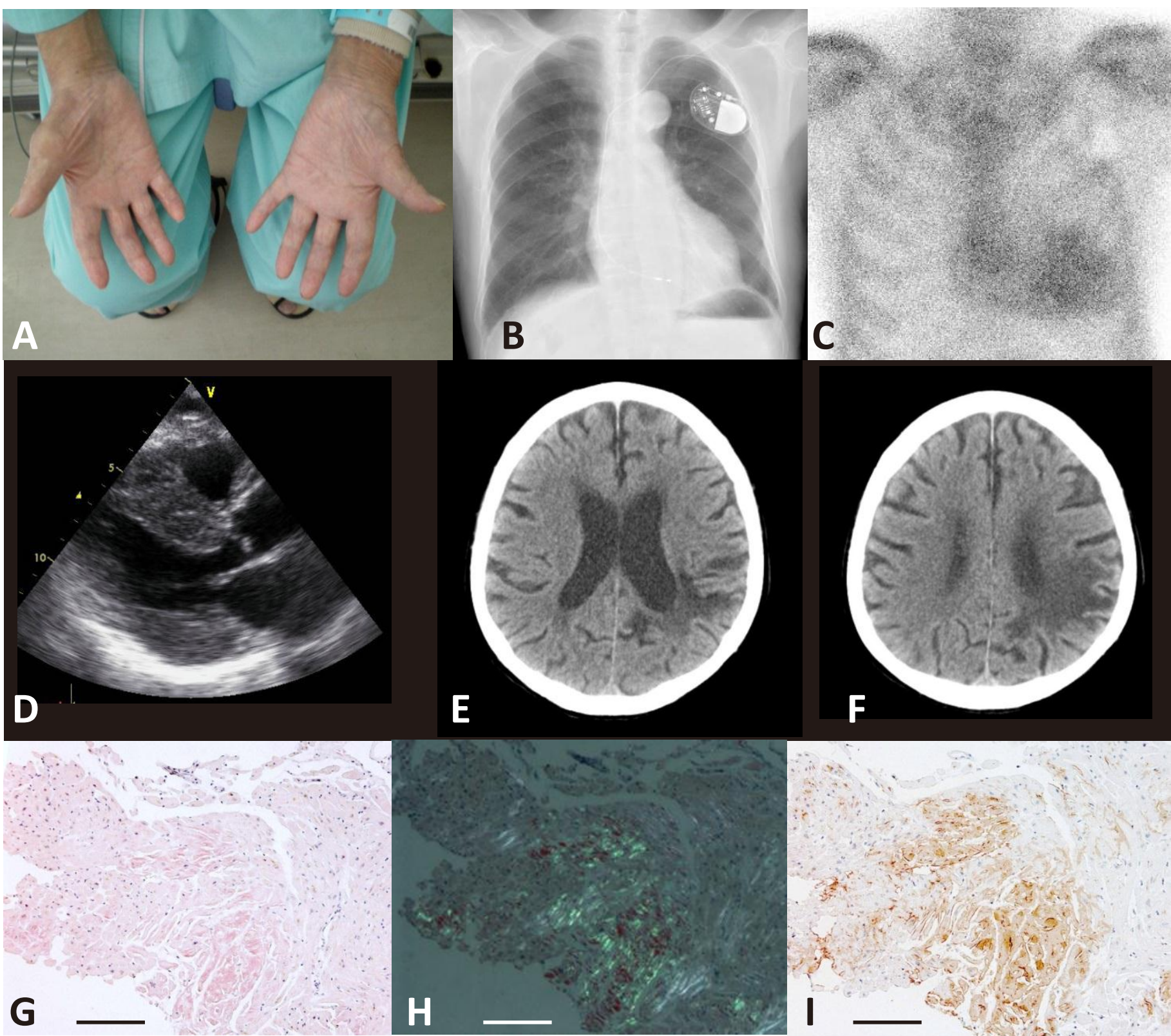

46

47

48

49

50

51

52 
Table 1. Comparison between carpal tunnel onset patients and cardiac onset patients

\begin{tabular}{|l|c|c|c|}
\hline & $\begin{array}{c}\text { Carpal tunnel } \\
\text { onset group }\end{array}$ & $\begin{array}{c}\text { Cardiac } \\
\text { onset group }\end{array}$ & $P$ \\
\hline Number of individuals & 17 & 14 & $0.53^{*}$ \\
\hline Sex (male $:$ female) & $14: 3$ & $10: 4$ & $0.01^{* *}$ \\
\hline Age at onset (mean \pm SD) & $66.5 \pm 8.6$ & $73.9 \pm 7.9$ & $0.58^{* * *}$ \\
\hline Age at diagnosis (mean \pm SD) & $73.5 \pm 8.7$ & $75.8 \pm 7.8$ & $<0.0001^{* * *}$ \\
\hline $\begin{array}{l}\text { The duration of illness from onset } \\
\text { to diagnosis (mean } \pm \text { SD) }\end{array}$ & $6.9 \pm 4.2$ & $1.9 \pm 2.7$ & \\
\hline
\end{tabular}

$P$-values were obtained using * $\chi^{2}$ test, $* *$ Student's t test, or *** Mann-Whitney U test 
Supplemental Table 1. Clinical and pathological features of systemic ATTRwt amyloidosis patients with antemortem diagnosis

\begin{tabular}{|c|c|c|c|c|c|c|c|c|c|c|c|c|c|c|c|c|c|}
\hline Patient & Gender & $\begin{array}{l}\text { Age at } \\
\text { onset }\end{array}$ & $\begin{array}{c}\text { Age at } \\
\text { diagnosis }\end{array}$ & $\begin{array}{l}\text { Time interval } \\
\text { between onset } \\
\text { and diagnosis }\end{array}$ & $\begin{array}{c}\text { Initial } \\
\text { symptom }\end{array}$ & CTS & $\mathrm{HF}$ & Af & $\begin{array}{l}\text { VT/ } \\
\text { VF }\end{array}$ & $\begin{array}{c}\text { AV } \\
\text { block }\end{array}$ & $\begin{array}{l}\text { BBB/ } \\
\text { IVCD }\end{array}$ & SSS & $\begin{array}{l}\text { Cardiogenic } \\
\text { embolism }\end{array}$ & CKD & $\begin{array}{c}\text { Other } \\
\text { complications }\end{array}$ & $\begin{array}{l}{ }^{99 m} \text { Tc-PYP } \\
\text { scintigraphy }\end{array}$ & $\begin{array}{l}\text { Sites of biopsy } \\
\text { where amyloid } \\
\text { was confirmed }\end{array}$ \\
\hline 1 & $M$ & 71 & 73 & 2 & $\mathrm{HF}$ & + & + & - & - & - & - & - & & - & & n.e. & $\mathrm{C}, \mathrm{Gl}$ \\
\hline 2 & M & 60 & 67 & 7 & CTS & + & + & - & - & + & + & + & $\mathrm{Cl}$ & + & & + & C, TST, Skin \\
\hline 3 & $\mathrm{M}$ & 65 & 75 & 10 & CTS & + & + & + & - & - & + & - & & + & & + & TST, GI \\
\hline 4 & $M$ & 60 & 76 & 16 & CTS & + & - & - & - & - & - & - & & - & & + & $\mathrm{Gl}$ \\
\hline 5 & $\mathrm{~F}$ & 97 & 97 & 0 & $\mathrm{Cl} / \mathrm{HF}$ & - & + & + & - & - & - & - & $\mathrm{Cl}$ & + & & + & Gl, Skin \\
\hline 6 & $M$ & 68 & 78 & 10 & CTS & + & + & - & - & - & - & - & & - & & + & TST \\
\hline 7 & $\mathrm{~F}$ & 70 & 74 & 4 & CTS & + & + & + & - & - & - & - & & - & & + & TST, GI \\
\hline 8 & $\mathrm{~F}$ & 75 & 85 & 10 & $\mathrm{HF}$ & - & + & + & - & - & + & - & $\mathrm{Cl}$ & - & cscs & + & Skin \\
\hline 9 & $\mathrm{~F}$ & 78 & 78 & 0 & $\mathrm{HF}$ & - & + & - & + & - & + & - & & - & & n.e. & C \\
\hline 10 & $\mathrm{M}$ & 67 & 70 & 3 & CTS & + & + & + & - & - & + & - & & + & $\mathrm{PN}$ & + & $\mathrm{C}, \mathrm{Gl}$ \\
\hline 11 & $\mathrm{M}$ & 65 & 72 & 7 & CTS & + & + & + & + & + & - & - & & + & & n.e. & C, Skin \\
\hline 12 & $M$ & 73 & 83 & 10 & CTS & + & + & + & - & + & + & - & $\mathrm{Cl}$ & + & & + & C, Skin \\
\hline 13 & $\mathrm{~F}$ & 77 & 84 & 7 & CTS & + & + & + & - & - & + & - & $\mathrm{TIA}$ & - & & + & Gl, Skin \\
\hline 14 & $M$ & 71 & 73 & 2 & $\mathrm{RI} / \mathrm{HF}$ & - & + & - & - & + & + & - & $\mathrm{RI}$ & + & LSCS & + & C, Skin \\
\hline 15 & $M$ & 73 & 73 & 0 & $\mathrm{HF}$ & - & + & + & - & - & - & - & & - & & n.e. & $C$ \\
\hline 16 & $\mathrm{~F}$ & 80 & 83 & 3 & CTS & + & + & + & - & - & - & - & & - & & + & Skin \\
\hline 17 & $M$ & 67 & 68 & 1 & $\mathrm{HF}$ & - & + & + & - & - & - & - & & - & cscs & + & $\mathrm{C}, \mathrm{Gl}$ \\
\hline 18 & $M$ & 69 & 71 & 2 & CTS & + & + & - & - & - & - & - & & - & & + & $\mathrm{C}, \mathrm{Gl}$, \\
\hline 19 & $M$ & 67 & 69 & 2 & $\mathrm{HF}$ & + & + & - & - & - & - & - & & - & $\mathrm{PN}$ & + & $\mathrm{C}, \mathrm{Gl}$, \\
\hline 20 & $\mathrm{M}$ & 44 & 47 & 3 & CTS & + & - & - & - & + & - & - & & - & & - & TST, GI \\
\hline 21 & $M$ & 77 & 77 & 0 & $\mathrm{HF}$ & - & + & - & - & + & - & - & & + & Cub & n.e. & C, Skin \\
\hline 22 & $\mathrm{~F}$ & 76 & 77 & 1 & $\mathrm{HF}$ & - & + & - & - & - & + & - & & + & & + & $\mathrm{Gl}$, \\
\hline 23 & $\mathrm{M}$ & 71 & 76 & 5 & CTS & + & - & - & - & - & - & - & & - & LSCS & + & $\mathrm{Gl}$ \\
\hline 24 & $\mathrm{M}$ & 68 & 68 & 0 & $\mathrm{HF}$ & - & + & - & - & - & - & - & Med A occl & - & & + & $C$ \\
\hline 25 & $\mathrm{M}$ & 78 & 81 & 3 & CTS & + & + & + & - & - & + & + & & - & & + & $C$ \\
\hline 26 & $M$ & 62 & 75 & 13 & CTS & + & + & - & - & - & + & - & & - & & + & C, Skin \\
\hline 27 & $M$ & 72 & 73 & 1 & $\mathrm{HF}$ & + & + & - & - & + & + & + & & + & & n.e. & $\mathrm{Gl}$ \\
\hline 28 & $M$ & 65 & 70 & 5 & $\mathrm{HF}$ & - & + & - & + & - & + & - & $\mathrm{Cl}$ & + & & n.e. & $\mathrm{C}, \mathrm{Gl}$ \\
\hline 29 & $M$ & 77 & 80 & 3 & $\mathrm{HF}$ & + & + & - & - & + & + & + & & + & & + & $\mathrm{Gl}$ \\
\hline 30 & $M$ & 61 & 66 & 3 & CTS & + & - & - & - & - & - & - & & + & & + & TST \\
\hline 31 & $M$ & 60 & 72 & 12 & CTS & + & + & + & - & + & + & - & & + & & + & C \\
\hline
\end{tabular}




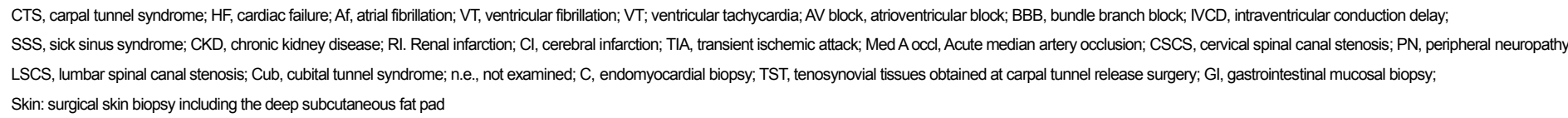

